\title{
HENRIQUE ANDRADE \\ (1960-2013)
}

MARIA JOÃO ALCOFORADO ${ }^{1}$

A 9 de Janeiro de 2013, faleceu Henrique Andrade, Geógrafo, Professor Auxiliar do Instituto de Geografia e Ordenamento do Território (IGOT) e Investigador do Centro de Estudos Geográficos da Universidade de Lisboa (CEG). Tinha 52 anos. Embora o soubéssemos doente, não se esperava tão repentina partida. Foi um enorme choque para familiares, amigos e colegas. Foi igualmente uma grande perda para o IGOT e para o CEG, de cuja Direcção fazia parte.

Henrique Andrade pouco falava da sua infância e adolescência. Como tão bem escreveu Viriato Soromenho-Marques, com quem leccionou a disciplina de Ambiente na Europa, ele era muito discreto e tinha uma "atenção ao mundo que quase se transformava em distracção para consigo próprio, tal a sua reserva e desprendimento pessoais" (Jornal de Letras, 23/01/2013). Essa reserva desaparecia, no entanto, quando de temas académicos se tratava.

Ingressou na Universidade de Lisboa em 1986, através de exame ad hoc; João Ferrão, então docente de Geografia da Faculdade de Letras, lembra-se de o ter entrevistado. Apenas conheci Henrique Andrade quando, em 1988/89, foi meu aluno de Climatologia local. Recordo-o sobretudo pela participação ocasional mas apropriada nas aulas. Em 1990, terminou a licenciatura em Geografia com a classificação de 14 valores. Seguiu-se o curso de Mestrado em Geografia Física e Regional, então com duração de quatro anos. A sua tese, de que fui orientadora, tratou do "Clima e Qualidade do ar em Lisboa", tema escolhido devido ao seu interesse e preocupação com o ambiente nas cidades e foi classificada com Muito Bom. Na altura do seu falecimento, o Prof Michel Erpicum, da Universidade de Liège, arguente no júri, relembrou as suas qualidades científicas.

Uns tempos depois, Henrique Andrade iniciou a tese de doutoramento, investindo num tema, inédito em Portugal na altura - a bioclimatologia humana, por que

1 Investigadora do Centro de Estudos Geográficos, Núcleo CliMA, Directora da Finisterra. Este texto foi escrito em colaboração com vários Investigadores dos núcleos CliMA e ANTECC do CEG-IGOT-UL 
se interessara durante um estágio no Instituto Meteorológico da Universidade de Freiburg, na Alemanha. Para exprimir numericamente o conforto térmico dos indivíduos, utilizou a Physiological Equivalent Temperature (PET), um índice bioclimático de expressão simples, que entra em conta com parâmetros radiativos, meteorológicos e outros respeitantes ao calor metabólico do corpo humano e seu isolamento pelo vestuário. Este índice, hoje frequentemente utilizado, era então praticamente desconhecido em Portugal. Foi com muito gosto que tornei a orientá-lo. A sua dissertação teve por título "Bioclima humano e temperatura do ar em Lisboa". Lisboa, que tão bem conhecia e que calcorreava frequentemente a pé, voltava a ser palco da sua investigação; além da bioclimatologia, aprofundou o estudo do clima urbano desta cidade, nomeadamente da sua vertente térmica.

Dada a inexistência de informação meteorológica urbana para Lisboa, Henrique Andrade concebeu e construiu o embrião daquilo que viria a ser a "rede de mesoscala" do CEG, na sequência de uma visita a Lisboa do Prof. Tim Oke, prestigiado climatólogo, consultor de um dos nossos projectos (CLIMLIS). Essa rede, depois equipada com abrigos modernos, foi durante muitos anos gerida por Henrique Andrade e continua em funcionamento, tendo os primeiros resultados sido publicados em 2007, no livro de homenagem ao Prof. Jorge Gaspar.

No decorrer da preparação da sua tese, admirei o seu espírito de iniciativa para desbravar novas temáticas, a sua inteligência, e o apurado sentido crítico que demonstrava. A dissertação foi discutida e aprovada em 2004, com Distinção e Louvor por unanimidade do júri, em que se incluía o Prof. Andreas Matzarakis, especialista de Biometeorologia, além de docentes das Universidades de Lisboa e de Coimbra.

As teses de Henrique Andrade e de António Lopes, que orientei simultaneamente, enquadraram-se em diversos projectos (JNICT, FCT, Câmara de Lisboa), tendo ambos tratado facetas diversas do clima urbano de Lisboa, na continuação dos trabalhos da minha própria tese de doutoramento. Numa altura em que as alterações climáticas globais voltavam a estar na ordem do dia, foram feitos diversos estudos que mostraram como a cidade também "faz" o seu clima; em muitas delas já ocorrem modificações de temperatura, projectadas para o fim do século XXI. No capítulo de um livro de Ecologia Urbana sobre as relações entre o aquecimento global e urbano, que escrevemos em colaboração, tentámos fazer o ponto da situação entre as diversas causas do aquecimento nas cidades ("globais", regionais, urbanas), que nuns casos se reforçam, noutros se opõem, mas a que raramente é atribuída a importância devida. Na sequência destas e doutras investigações, começaram a ser preparadas orientações climáticas para o ordenamento das cidades e sugeridas adaptações às alterações, que já não se conseguem evitar.

Paralelamente, desde 1991, Henrique Andrade ensinava, primeiro no Departamento de Geografia da FLUL e, a partir de 2010, no IGOT. Além de disciplinas de Climatologia (básica ou aplicada) e Ambiente, que preferia, leccionou matérias de Geografia Física, Geologia, Cartografia, Análise de Dados e Modelação, entre muitas outras, tanto ao nível da graduação, como em cursos de mestrado e de doutoramento. 
Preparava e participava na elaboração dos programas das disciplinas, organizava as aulas com muito cuidado, introduzindo todos os anos inovações e bibliografia recente. Explicava a matéria com rigor, concisão e entusiasmo, estava sempre pronto para atender os estudantes, mas era exigente e tinha pouca paciência para quem se mostrava desinteressado. Leccionou também noutras instituições de ensino como a Faculdade de Arquitectura da UTL, o ISCTE e o IST.

Quando terminou a tese de mestrado, ingressou na Área de Investigação de Geo-Ecologia do Centro de Estudos Geográficos da Universidade de Lisboa, coordenada sucessivamente pelas Professoras Suzanne Daveau, Maria Eugénia Moreira e por mim própria. Em 2008, os investigadores do CEG reorganizaram-se e Henrique Andrade integrou o núcleo "Clima e Mudanças Ambientais" (CliMA), que tenho vindo a coordenar. Contribuiu muito activamente para a formulação dos objectivos do núcleo e enriqueceu-o com as suas obras, projectos e orientações de estudantes. Foi um exemplo de dedicação abnegada à investigação, evitando, sempre que possível, as luzes da ribalta. Os seus colaboradores mais directos apreciavam a riqueza do contacto com ele em termos humanos, científicos e culturais (sobretudo no campo da literatura).

Nos nove anos que se seguiram ao doutoramento, Henrique Andrade, envolveu-se em diversas pesquisas que, partindo da Climatologia, faziam ponte com disciplinas das Ciências Sociais, seja no seio do CEG, seja em colaboração com outras instituições nacionais e estrangeiras, orientando estudantes nestas temáticas.

Publicou resultados da sua tese de doutoramento e aprofundou o estudo da bioclimatologia humana, no âmbito do projecto FCT UrbKlim, calculando diversos índices de conforto, a partir de informação meteorológica obtida in situ. Nesses estudos integrou a percepção do ambiente térmico pelos utentes dos espaços estudados, baseado em inquéritos, tendo publicado um artigo com o título "Perception of temperature and wind by users of public outdoor spaces". Data deste período o renovar do seu interesse pela importância ambiental dos espaços verdes, tendo submetido a concurso diversos projectos pluridisciplinares, bem classificados, mas lamentavelmente não financiados. Temos em mente relançar esta investigação, dando continuidade a uma temática interessante e de grande actualidade. Incansável na preparação de novas candidaturas, viu aprovado o projecto internacional "Urban tourism and climate change" (programa Urban-Net), em colaboração com as Universidades de Gotemburgo e de Ankara. Dedicou-se a ele com muito entusiasmo, transmitido à bolseira do projecto, Raquel Machete, a qual iniciou uma dissertação sobre o tema, sob sua orientação.

Divulgou os resultados das suas pesquisas em diversas revistas internacionais tais como International Journal of Biometeorology, Building and Environment, Landscape and Urban Planning, Theoretical and Applied Climatology, International Journal of Biometeorology e também na Finisterra, nas quais era também frequente revisor científico. Foi autor e co-autor de numerosos artigos e de capítulos de livros, publicados em Portugal e noutros países, um dos quais em língua chinesa. Foi membro activo de diversas Associações, de que se destaca a International Association on 
Urban Climate (IAUC) e a International Society of Biometeorology (grupo 11: Climate, Tourism and Recreation). Correspondia-se com colegas de todo o mundo, discutindo problemas que iam surgindo nas diversas investigações. O seu falecimento foi anunciado na primeira página do fascículo 46 de "Urban News", publicação trimestral da IAUC, em cujo congresso, realizado em Dublin, em Agosto de 2012, Henrique Andrade participou, apesar de já estar bastante doente. A notícia inclui um texto que um grupo de Investigadores dos núcleos CliMA e AntECC do CEG divulgaram sobre ele em inglês (http://urban-climate.org/newsletters/ IAUC046.pdf).

Numa publicação recente (2013) da União Europeia, Science for Environmental Policy, foi feita referência à importância do artigo por Oliveira, Andrade e Vaz (2011), intitulado "The cooling effect of green spaces as a contribution to the mitigation of urban heat: a case study in Lisbon", publicado na revista Building and Environment. "New research from Portugal has demonstrated that even a small community garden can provide a significant cooling impact that can help efforts to adapt to climate change" é o título da referência, que remete para um extenso resumo do artigo.

As relações tempo atmosférico-saúde continuaram a interessar Henrique Andrade, que tinha entre mãos dois estudos, um sobre a acção do "frio" na saúde no centro de Portugal e outro sobre a relação entre as descargas eléctricas e as asmas (no projecto Raiden, coordenado por Marcelo Fragoso). Conseguiu também que o estudo das relações entre o calor e o frio, por um lado, e a mortalidade e morbilidade, por outro, tratados sob uma perspectiva geográfica, fosse tema de pesquisa de mestrandos e de um doutorando. Paulo Canário, orientado por Henrique Andrade, está a terminar a redacção da sua dissertação de doutoramento com o título "Modelação Espacial da Mortalidade Associada a Extremos Térmicos na Área Metropolitana de Lisboa. Situação Presente e Perspectivas Futuras".

Sempre que com ele colaborei pude apreciar o investimento que fazia na procura de informação, a profundidade de assimilação da bibliografia, a sua excelente capacidade de síntese e a sua inteligência criativa. Devo também ressaltar a sua generosidade nos trabalhos em colaboração com vários autores, prontificando-se sempre a executar também as tarefas mais morosas. Discutia com colegas de outras áreas os problemas da investigação, mesmo dos não directamente relacionados com o seu trabalho, fazendo pertinentes observações.

Henrique Andrade era um homem culto, de gostos eclécticos, que aproveitava as viagens de combóio ou de autocarro para a Universidade para ler, sendo visita frequente de alfarrabistas. Também era apreciador de música, que ouvia quando passeava junto ao mar, na Parede, onde residiu. Gostava de observar a natureza e conhecia o nome das plantas e de muitas aves dos jardins de Lisboa, até dos menos vulgares, como a espécie exótica que parece estar em rápida expansão nos últimos anos, o periquito-de-colar, que poisa nos choupos junto à Torre do Tombo. Tinha um sentido de humor muito particular e era por vezes tão intransigente com os outros como com ele próprio. 
A investigação em que se empenhava prosseguiu até ao fim (poucos dias antes de morrer esteve a trabalhar no CEG), apesar dos evidentes problemas de saúde. Muitas linhas de investigação ficam em aberto, muitos artigos incompletos, alguns em colaboração com colegas que trabalharam em Lisboa, como Agota Szucs (Hungria) e Victor Barradas (México). No núcleo CliMA do CEG decidimos cerrar fileiras e congregar esforços para não deixar perder as suas ideias, os seus contactos, os seus trabalhos.

Gostaria que tivesse ficado expressa a grande amizade que unia Henrique Andrade a alguns de nós, uma amizade contida, feita de laivos de conversas, algumas delas silenciosas, e de múltiplos episódios académicos. Era assim que Ele era. Faz-nos muita falta, não só como o Amigo, discreto mas sempre presente, mas também como o Colega que incutia entusiasmo e perseverança na nossa investigação. Como escreveu Victor Barradas, da Universidade do México: "Creo que el IGOT/ CEG-UL queda en deuda con él, y también todos los lisboetas (..); hemos perdido a un gran estudioso del clima urbano y sus efectos". Por isso, queremos honrar a sua memória e continuar a sua obra. 